Sheridan College

SOURCE: Sheridan Institutional Repository

Publications and Scholarship

Faculty of Humanities \& Social Sciences

(FHASS)

2015

Cooking as Leisure Activity

Michelle K. Szabo

Sheridan College, michelle.szabo@sheridancollege.ca

Follow this and additional works at: https://source.sheridancollege.ca/fhass_publications

Part of the Food Studies Commons, and the Leisure Studies Commons

\title{
SOURCE Citation
}

Szabo, Michelle K., "Cooking as Leisure Activity" (2015). Publications and Scholarship. 18.

https://source.sheridancollege.ca/fhass_publications/18

\section{(c) $($ ) $\Theta$}

This work is licensed under a Creative Commons Attribution-No Derivative Works 4.0 License. This Book Chapter is brought to you for free and open access by the Faculty of Humanities \& Social Sciences (FHASS) at SOURCE: Sheridan Institutional Repository. It has been accepted for inclusion in Publications and Scholarship by an authorized administrator of SOURCE: Sheridan Institutional Repository. For more information, please contact source@sheridancollege.ca. 


\section{@SAGE reference The SAGE Encyclopedia of Food Issues Cooking as Leisure Activity}

Contributors: Michelle K. Szabo

Edited by: Ken Albala

Book Title: The SAGE Encyclopedia of Food Issues

Chapter Title: "Cooking as Leisure Activity"

Pub. Date: 2015

Access Date: October 15, 2019

Publishing Company: SAGE Publications, Inc.

City: Thousand Oaks,

Print ISBN: 9781452243016

Online ISBN: 9781483346304

DOI: http://dx.doi.org/10.4135/9781483346304.n101

Print pages: $300-303$

(C) 2015 SAGE Publications, Inc. All Rights Reserved.

This PDF has been generated from SAGE Knowledge. Please note that the pagination of the online version will vary from the pagination of the print book. 
Broadly, cooking can be defined as the preparation of food for human consumption. A leisure activity, or hobby, is an activity that is done outside of paid employment and necessary domestic work, typically for its intrinsic pleasures rather than as a means to an end. Cooking as a leisure activity (or hobby), then, is food preparation in the home that is done primarily for the pleasures and satisfactions of the process rather than simply as a way to produce food for survival.

While it is difficult to define a person strictly as a hobby or leisure cook-most people cook out of necessity at least some of the time-we can identify some common characteristics of leisure cooking. Cooking as a leisure activity typically involves procuring special ingredients, kitchenware, food knowledge, and culinary skills. It is usually an involved and time-consuming process with "interesting," "exciting," "authentic," or "exotic" food as the goal. Hobby cooks also often construct their identities and social circles around cooking, which means that they like to share their kitchen creations with others through dinner parties, food blogs, and the like. Many leisure cooks might be described as "foodies"-people with a passion for eating and learning about food in general. A key distinction between foodies and leisure cooks is that foodies do not necessarily cook; they may indulge in their passion for food by eating out.

Leisure cooking is of interest to food scholars because it is a relatively recent phenomenon. Although the incidence of leisure cooking is difficult to measure (few large-scale studies focusing on leisure vs. day-to-day cooking exist), it seems to have gained popularity around the turn of the 21 st century as a result of a confluence of factors. These include the rise of food media and "foodtainment," the popularization of "ethical" eating in a time of environmental crises, and the proliferation of convenience foods, which reduce the necessity for regular, day-to-day food preparation. Hobby cooking is also a strongly gendered phenomenon. A rare 2008 study on the topic by British market research firm the Future Foundation found that $52 \%$ of men versus $40 \%$ of women in the United Kingdom thought of cooking as a hobby and not a chore (http://futurefoundation.net/).

The remainder of this entry focuses on when and why cooking came to be viewed as a leisure activity, what characteristics of cooking make it leisurely, why it is that men in more privileged social strata are most likely to see cooking as a hobby, the competing discourse of cooking as a "chore," and recent debates about the difficulties defining cooking as "leisure" or not.

\section{Factors Contributing to the Rise of Leisure Cooking}

Leisure cooking is largely a phenomenon of modern industrial societies, where household technologies (e.g., indoor plumbing, electrical appliances) reduce the drudgery involved and the ubiquity of ready-made foods makes cooking more optional. When it is no longer labor-intensive or strictly necessary, cooking can become a pleasant pursuit one chooses to do in free time. Leisure cooking has also arisen with the narrowing of class divides. In earlier societies where the upper classes engaged in unproductive leisure to distinguish themselves from the laboring classes (e.g., hunting for sport rather than for food), food procurement and preparation were seen as debasing. Another factor contributing to the rise of cooking as a hobby is the relationship between leisure and identity in late modern capitalism. In post-Fordist economies, where the lifetime job is a thing of the past, people create their identities less through their paid work and more through their "lifestyle"-what they buy and how they spend their free time. In this context, leisure cooks are not only involved in cooking per se, but in the modern project of creating the self.

A more recent contributor to the popularity of leisure cooking is the rising presence of food and "foodtainment" in popular culture. The Food Network was launched in the United States in 1993, and in the years since, there has been an explosion of TV shows, books, magazines, blogs, and websites devoted to food and cooking worldwide. In addition to raising the profile of cooking, these media take a particular approach to food. Whereas earlier cooking shows and books were primarily meant to instruct (e.g., shows from 1960s and 1970s had personalities like Julia Child in the United States and Delia Smith in the United Kingdom), food media around the turn of the 21st century are heavily geared to entertainment. Through cooking competitions, performances, and highly stylized food imagery, food and cooking are portrayed as a sensory spectacle.

Page 2 of 6

The SAGE Encyclopedia of Food Issues 
Related to this is the proliferation of gourmet cookware, kitchen gadgets, and "trophy kitchens." According to a 2012 Euromonitor report, the global cookware (stove top and oven equipment) and kitchenware (kitchen utensils and food storage products) industry alone is now worth US $\$ 45$ billion. This cooking equipment is promoted as increasing not only cooking enjoyment but also the stylishness and prestige of the home cook. One indication of the connection between kitchen products and identity is the growing availability of kitchenware in a variety of colors, which consumers can use to personalize their kitchen spaces. The idea of cooking as entertainment has also been fueled by the economic recession following the 2008 world financial crisis. Conscious of their spending, people turned away from activities like eating out to what marketers call "hometainment." According to Euromonitor, the global cookware industry showed continuous growth from 2006 to 2011 despite the economic downturn. It should be noted, however, that cooking media and gadgets do not necessarily inspire consumers to cook. Some scholars liken recent food media to pornography in that the pleasure is not in the doing but in the watching. Likewise, kitchen paraphernalia may be more for show than for use.

A final factor contributing to the rise of cooking as a leisure activity is the nature of early-21st-century food politics. With the release of highly influential films and books criticizing the industrial food system (Food Inc., The Omnivore's Dilemma), some people see their food habits as a form of activism. It is notable that "ethical eating" contrasts with other forms of activism that emphasize self-sacrifice for the greater good (e.g., hunger strikes, ascetic rejections of consumerism). With the former, the emphasis is on how activities like cooking from scratch yield both personal pleasures, such as the good taste of freshly made food, and collective benefits, such as reducing the environmental and social harms of the processed food industry. "Ethical eating" is also strongly linked to the neoliberal political ethos of this period, which promotes the idea that individual selfinterest benefits society as a whole. In this sociopolitical climate, leisure cooking can be seen as an enjoyable way in which individuals can effect change.

\section{Leisurely or Pleasurable Aspects of Cooking}

In qualitative research on cooking, people give a variety of reasons for enjoying cooking. Many mention the sensual pleasures of tasting, smelling, and manipulating food or the creative gratification of coming up with new dishes. Others find cooking therapeutic or relaxing. As it requires some concentration, cooking can take one's mind off of life's challenges. Cooking can also be fulfilling, especially when it is time- and labor-intensive, because it requires physical and mental skill and effort. It gives people a sense of challenge-planning and executing a meal-followed by one of accomplishment-feeding oneself and loved ones. For this reason, hobby cooking can be categorized with other skilled hobbies such as archery or woodworking and distinguished from more passive or unskilled hobbies such as watching TV or window shopping. Cooking is also an activity that can garner recognition, especially for leisure cooks, who tend to make relatively extravagant meals for guests rather than day-to-day meals for the household. Moreover, cooking can satisfy a desire to connect with nature and one's subsistence. This is especially relevant in late modern capitalism, when people rarely make what they consume (e.g., food, clothing, housing) with their own hands.

\section{Gender, Class, and Race and Leisure Cooking}

There are patterns in terms of which social groups tend to see cooking as a leisure activity. First, men tend to cook as a leisure activity more than women. In fact, the term gastrosexual (a combination of "gastronomy" and "metrosexual"), first coined in 2008 by the market research firm the Future Foundation, is gaining prominence in food media and on food blogs to describe men who see cooking as a passion rather than as a chore. Feminists argue that this gender distinction relates to the division of household labor. National statistics indicate that women in the early 2000s still do about twice as much cooking and cleaning up as men in North America, Britain and Australia. Moreover, it is women who tend to do the more mundane, day-to-day cooking, while men tend to cook on weekends and special occasions. This means that women often have to feed a 
household even when they are tired or uninspired. It also means that it is typically a woman's job to look after potentially stressful considerations such as nutritional health, food safety, family food likes and dislikes, and food allergies.

The larger division of household duties is also important. Women still do more of other types of housework and carework (e.g., child care, cleaning) than men, especially in heterosexual relationships. If a man can devote his full attention to making a meal because his female partner is changing diapers, doing laundry, or washing dishes, this makes it easier for him to see cooking as a break from daily life.

Another issue related to gender and cooking approach is the recognition that people receive for their cooking. Since it is still relatively rare for men to cook in the home, and since they tend to cook more extravagant meals for special occasions, men receive praise and status for home cooking. Women's cooking, on the other hand, is more often taken for granted.

For all of these reasons, men are more often hobby cooks than are women. Food media reinforce this pattern. When men are the hosts of cooking shows, or the target readers of food writing, cooking is usually portrayed as a hobby. Women's cooking in food media, in contrast, tends to be portrayed as routine domestic work done for loved ones.

Income and food knowledge, which relates to social class, also shape the extent to which people view cooking as leisure. For cooking to hold one's interest as a hobby, it must be taken out of the realm of the mundane. One way hobby cooks do this is by procuring special ingredients, cookbooks, and kitchen implements. However, these can be very costly, especially over the long term, and thus out of reach for people with lower incomes. Furthermore, what is seen as necessary culinary knowledge for the hobby cook tends to be more accessible to the middle and upper classes. This is because these classes have a disproportionate influence on gourmet food writing, food TV, and other food media.

Race and class hierarchies also influence who sees cooking as a leisure activity. Just as women have been obligated to cook as a form of unpaid work, so have marginalized groups who had to cook for others as forms of paid and coerced work. For example, in North America, blacks worked historically in kitchens as slaves. More recently, Latinos and Filipinos are overrepresented as domestic cooks. Many other ethnoracial minorities now own and run modest restaurants. In general, visible minorities do much of the frontline food industry work that is unpleasant, exhausting, low in prestige, or even dangerous (e.g., slaughterhouse work). As a result, some ethnoracial minorities who themselves, or whose family members, have been involved in paid or forced food labor associate cooking with oppression. It should be noted, however, that the relationship between gender, class, and leisure cooking has been more firmly established statistically than that between race and leisure cooking.

\section{Counterdiscourses: Cooking as a Chore}

While much of the discourse of food media and advertising in the early 21 st century portrays cooking as a leisure activity, there is also a prominent counterdiscourse in which cooking is portrayed as a chore. A major contributor to this alternative discourse is fast food and convenience food advertising. Ads of this genre typically imply that a processed food product is necessary because cooking from scratch is time-consuming and burdensome. This discourse gained prominence with women's growing participation in the workforce and the concurrent proliferation of convenience foods over the 20th century. Nonetheless, the idea that cooking involves unpleasant work has been promoted by the convenience food industry since it first began heavily marketing frozen, canned, and dried products to housewives in the 1950s.

This negative conceptualization of cooking also surfaced in first-wave feminist writings around the turn of the 20th century and then again in second-wave feminist thought in the 1960s and 1970s. The idea was 
that time spent cooking and doing other domestic tasks prevented women from becoming involved in paid work and public life, or vice versa, that paid work commitments left little time for women to enjoy cooking. As women's workforce participation approached that of men's in the latter decades of the 20th century, cooking was labeled a part of women's "double day" or "second shift" (most notably in the feminist sociologist Arlie Hochschild's book The Second Shift). Cooking thus became a symbol of gender oppression. During this time, the notion that cooking was part of an old-fashioned or oppressive domestic femininity was also evident in popular TV shows such as Roseanne (1988-1997) and Sex and the City (1998-2004).

In the early 2010s, the "cooking as a chore" discourse exists alongside an opposing discourse where domesticity is celebrated as a feminist endeavor. Women dubbed "femivores" and "radical homemakers" aim to challenge environmental and social injustices by engaging in activities such as food growing, cooking from scratch, and home preserving. Though these activities are often a fulltime (and not just leisure) pursuit for these women, there is overlap with the "cooking as leisure" discourse in that leisure cooks, femivores, and radical homemakers all celebrate the sensual and social gratifications of making food.

\section{Cooking as Leisure or Work? Feminist and Poststructural Perspectives}

Though people's perceptions of cooking are often dichotomized in popular culture (they are said to conceptualize cooking as either leisure or work), it is actually difficult to draw this distinction for everyday home cooks. As noted, cooking can be seen as a leisure activity when it is done primarily for the pleasures of the process rather than as a way to produce the food necessary for survival. But cooking study participants often observe that they cook both for pleasure and out of necessity. Indeed, feminist scholars point out that carework activities like child care and cooking do not neatly fit into the categories of "work" and "leisure" because these concepts grew out of conditions in the masculine/public realm. Specifically, the concept of "work" revolves to a large degree around the traditional (male) job, which is bounded in time (the workday) and space (the workplace), and can thus be easily contrasted with the times and spaces of "leisure" (e.g., evenings and weekends, often in or around the home). Housework, including cooking, is difficult to define because it takes place in both traditional "work" and traditional "leisure" contexts.

Poststructural ideas about modern leisure also contribute to the idea that cooking is difficult to categorize. In knowledge economies with increasing numbers of people working from home, and modern technologies (e.g., the Internet) bringing leisure into the workplace, the boundaries between work and leisure are blurring for paid workers as well. Thus, leisure scholars increasingly see modern leisure as fragmentary and context dependent.

All of these ideas challenge the supposition that cooking can be conceptualized categorically as either work or leisure. In reality, some people see cooking as more leisurely than others, and most people experience cooking as work in some contexts and leisure in others. For example, cooking might feel more like leisure when people do it as a creative outlet, or while listening to music or socializing with others, and it might feel more like work when people feel rushed or uninspired.

See alsoBlogging; Celebrity Chefs; Cookbooks and the Publishing Industry; Cooking Competitions; DIY Food Movement; Family Meals/Commensality; Farmers' Markets, Cooking With Seasonal Produce; Trophy Kitchens

Michelle K. Szabo

http://dx.doi.org/10.4135/9781483346304.n101

10.4135/9781483346304.n101

\section{Further Readings}


Aitchison, C. (2003). Gender and leisure: Social and cultural perspectives. London, UK: Routledge. Cairns, K., Johnston, J., \& Baumann, S. (2010). Caring about food: Doing gender in the foodie kitchen. Gender \& Society, 24(5), 591-615.

Euromonitor International. (2012). Homewares: Category overview (Global Briefing). London, UK: Author. Giddens, A. (1991). Modernity and self-identity: Self and society in the late modern age. Stanford, CA: Stanford University Press.

Hollows, J. (2003). Oliver's twist: Leisure, labour and domestic masculinity in The Naked Chef. International Journal of Cultural Studies, 6(2), 229-248.

Hollows, J. (2006). Feminism, post-feminism and domesticity. In J. Hollows \& R. Moseley (Eds.), Feminism in popular culture (pp. 97-118). New York, NY: Berg.

Johnston, J., \& Baumann, S. (2010). Foodies: Democracy and distinction in the gourmet foodscape. New York, NY: Routledge.

Short, F. (2006). Kitchen secrets. The meaning of cooking in everyday life. Oxford, UK: Berg.

Soper, K., Ryle, M., \& Thomas, L. (Eds.). (2009). The politics and pleasures of consuming differently. London, UK: Palgrave.

Szabo, M. (2013). Foodwork or foodplay? Men's domestic cooking, privilege and leisure. Sociology, 47(4), 623-638.

Szabo, M. (2014). Men nurturing through food: Challenging gender dichotomies around domestic cooking. Journal of Gender Studies, 23(1), 18-31. 